\title{
CHARACTERIZATION OF KARST COLLAPSE HAZARD BASED ON GROUNDWATER FLUCTUATIONS IN QINGYUN VILLAGE, GUIGANG, GUANGXI, CHINA
}

\author{
Xiaozhen Jiang, Mingtang Lei, Zhende Guan \\ Institute of Karst Geology, CAGS, Guilin, China, jiangxiaozhen2005@hotmail.com
}

\author{
Yongli Gao \\ Department of Geological Sciences, Center for Water Research, University of Texas at San Antonio, TX 78249 USA, \\ yongli.gao@utsa.edu
}

\begin{abstract}
In the past decade, sinkhole collapses occurred every year at Qingyun village, Guigang, Guangxi, China. Groundwater fluctuations were thought to cause these collapses. A high resolution real-time monitoring system was established to assess sinkhole hazards in this area. Monitoring of water levels of residential and community wells indicate a water shortage in the shallow karst aquifer, which is greatly influenced by precipitation in the study area. Domestic and irrigation water usage could result in frequent and dramatic changes of water level in the shallow karst aquifer. By comparing with real-time monitoring of the groundwater level in a referenced area with no sinkhole collapsing event, a characterization process was developed to assess sinkhole hazards in the Qingyun village area. Characterization criteria include daily water level fluctuations of karst aquifer, recovery of water level in the karst aquifer, maximum declining rate of water level in the karst aquifer, and sinkhole distribution within $500 \mathrm{~m}$ of water pumping activity. The characterization process was then applied to the study area to identify and prioritize areas that are most likely to be affected by human activities. This characterization process could be used by engineers and land-use planners to prioritize water usage and to prevent the development of soil voids and humaninduced sinkholes in active karst areas.
\end{abstract}

\section{Introduction}

Sinkhole hazard assessment has been focused on structural controls, bedrock geology, depth to bedrock, epikarst characteristics, geomorphology, distribution of karst features especially sinkhole distribution, water level to the top of bedrock, pumping rate and duration, $\mathrm{N}$-value of Standard Penetration Test (SPT), soil voids and caves encountered during drilling process, fluid loss and water level changes associated with drilling (Lei et al, 2000; Zisman, 2001; Hu et al., 2003; Waltham et al., 2005; Gao et al., 2005; Gao and Alexander, 2008; Li et al., 2008). However, previous assessments on potentiometric surface and water level changes were used for regional scale assessment of sinkhole hazards. A relatively simple monitoring method is needed to assess potential karst collapses at specific construction or engineering project sites.

In the past decade, sinkhole collapses occurred every year at Qingyun village, Guigang, Guangxi, China. Most sinkholes are round shape ranging from $0.5-5 \mathrm{~m}$ in diameter and $1-5 \mathrm{~m}$ in depth. These collapses may affect the ongoing construction of a new natural gas pipeline through the village. The primary goal of this project is to develop a high resolution real-time monitoring system to assess sinkhole hazards along the proposed natural gas pipeline in this area.

\section{Study Area}

The study site is located at Qingyun village, Guigang city, $156 \mathrm{~km}$ east of Nanning, the capital city of Guangxi province (Figure 1). This area belongs to the central -south subtropical monsoon region. Average annual temperature is $21.5^{\circ} \mathrm{C}$ and precipitation ranges between 1415.4 to $1731.8 \mathrm{~mm}$ per year with $75 \%$ occurring during the raining season between April and September.

This is a typical fenglin and tower karst plain. The altitude of the ground surface is about $43.1-50.3 \mathrm{~m}$. Land-use is mainly agriculture for crops and small patches of rice paddies. The unconsolidated sediments above bedrock are Quaternary alluvium and colluvium with a thickness ranging between $2.0 \mathrm{~m}$ and $10.0 \mathrm{~m}$. Quaternary deposits are clay and silty clay containing gravels. The bedrock is thick light-gray to dark-gray limestone belonging to Devonian Donggangling formation. Limestone is massive 


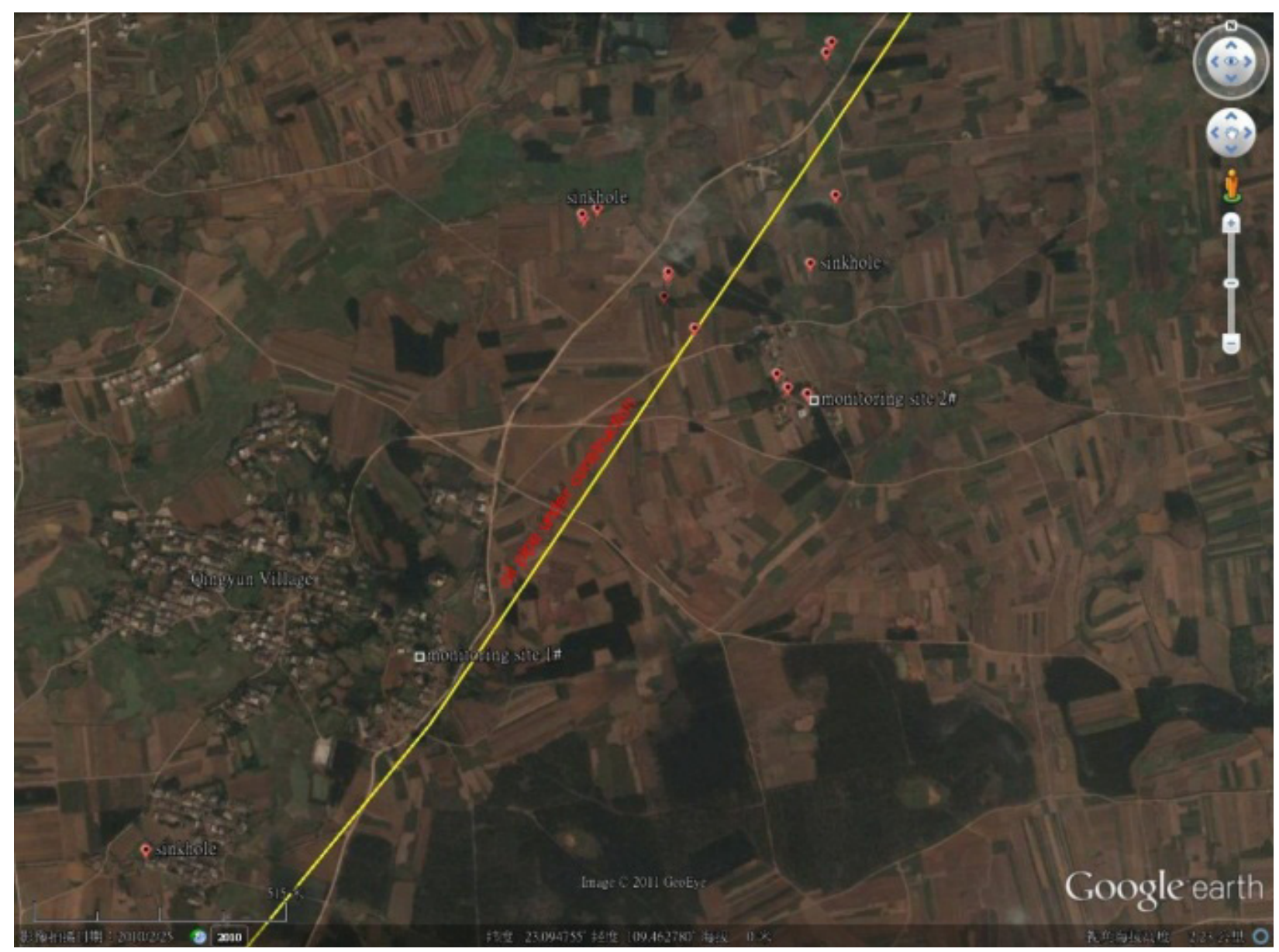

Figure 1. Google Earth Map of the study area showing sinkhole distribution and natural gas pipeline.

with highly fractured exposures. The study area is also located on the west limb of Tantang - Yunbiao Syncline.

\section{Methodology}

No surface water resources exist in the study area. Shallow karst water is scarce and directly affected by precipitation. Groundwater is the only source of water for agriculture, industry, and domestic water supplies. Pumping groundwater has been thought to induce many sinkholes in this area (Figures 1 and 2).

A comparative study of hydrodynamic changes of karst water is conducted in active karst areas with sinkhole collapses and inactive karst areas without sinkholes. Geokon pressure transducers and data loggers were used to monitor real-time water level changes. Based on previous model experiments on sinkhole and soil void formations, measurement intervals need to be less than 30 minutes to capture hydrodynamic controls on sinkhole collapses. Measurement intervals were set at 10 -30 minutes on this project.
Four monitoring sites were established at existing water wells. Sites 1 and 2 are located in Qingyun village where many sinkholes collapsed in the past. Sites 3 and 4 are located in Jitang village where no sinkhole collapses occurred in the past. The distance between Qingyun village and Jitang village is approximately $8 \mathrm{~km}$.

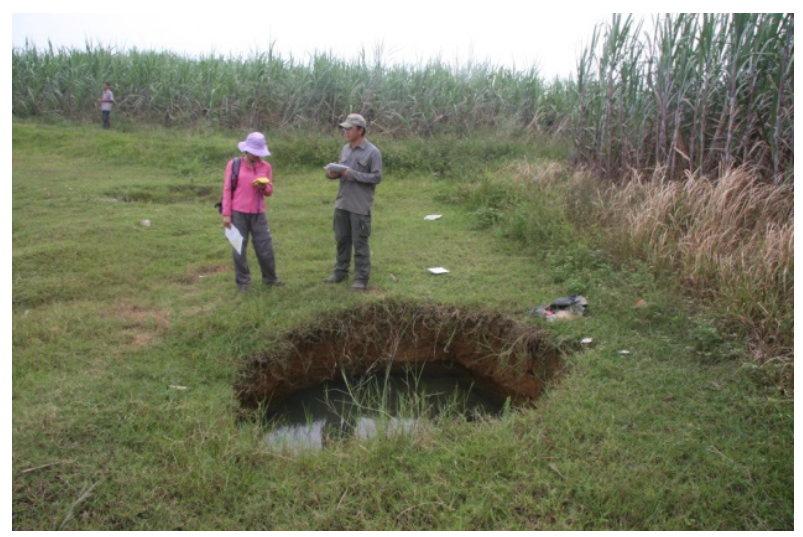

Figure 2. A collapsed pit caused by groundwater pumping. 


\section{Results and Discussion Changes of Hydrodynamic Conditions}

Site 1 - Hydrodynamic Changes

Monitoring site 1 is located at a domestic handdug well with a depth of $11.4 \mathrm{~m}$. Water levels were monitored between February 28 and September 2, 2011 with a measurement interval of 30 minutes and 8919 measurements were collected.

Figure 3 shows water level changes in the duration of the monitoring study. The lowest water level is $10.47 \mathrm{~m}$ below surface at dry season and the highest water level is $0.41 \mathrm{~m}$ during monsoon season. The range between the highest water level and lowest water level is 10.06 $\mathrm{m}$. The thickness of Quaternary sediment is between 6 and $10 \mathrm{~m}$ in this area. Therefore, karst water has been fluctuating around the top of the bedrock.

Groundwater level is affected not only by precipitation but leakage of irrigation water for agriculture as well. For example, no rainfall occurred in mid-August and the regional water level declined in the study area. However, the water level at site 1 remains at a higher level similar to the level of monsoon season. Further investigation reveals that significant leakage occurred along irrigation channels during a high demand of water for agriculture in mid-August.

Figure 4 illustrates water level changes caused by pumping activities on August 21. Groundwater was pumped out 4 times between 8:00 and 15:00. A decline of $5.2 \mathrm{~m}$ was caused by initial pumping between 8:00 and 10:00. The duration of the subsequent pumping was relatively short (30 minutes) and caused minor decline of the water level at approximately $1 \mathrm{~m}$. It took more than 6 hours for the recovery of the water level after the last pumping. In addition, the rate of water level changes is an important factor triggering sinkhole collapses. The maximum declining rate is $6.58 \mathrm{~cm} / \mathrm{min}$ and the maximum rate of water level rise is $4.3 \mathrm{~cm} / \mathrm{min}$.

\section{Site2 - Hydrodynamic Changes}

Monitoring site 2 is located at a domestic hand-dug well with a depth of $6.75 \mathrm{~m}$. Water levels were monitored between December 5, 2007 and January 28, 2008 with a measurement interval of 10 minutes and 144 measurements were recorded each day. Monitoring study occurred during a very dry season with the maximum decline of water level and frequent water level changes caused by water pumping.

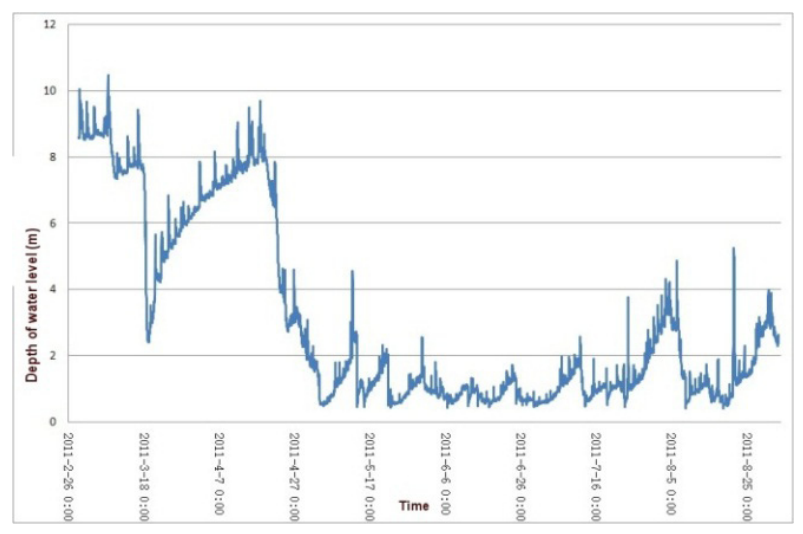

Figure 3. The variation of groundwater level of monitoring site 1 .

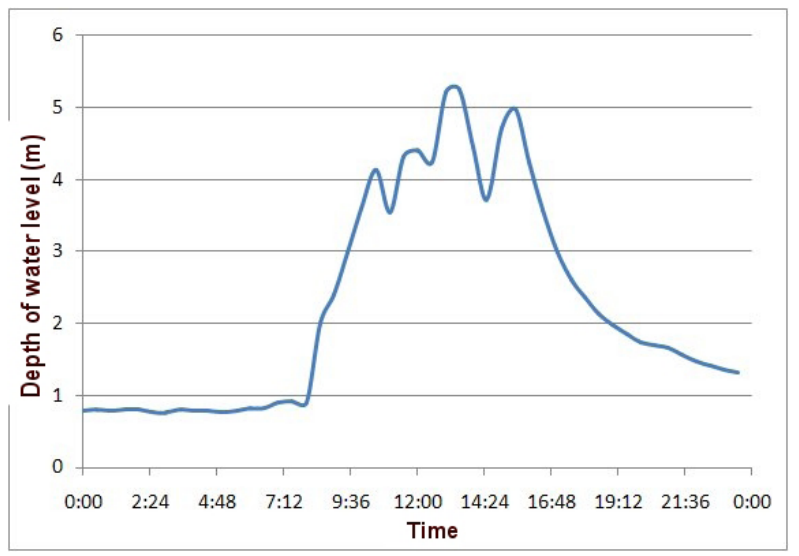

Figure 4. The variation of groundwater level of monitoring site 1 caused by pumping activities on August 21, 2011.

The range of water level change is within $3 \mathrm{~m}$ and groundwater is affected mainly by precipitation. For example, rainfall started in the morning on January 25 , 2008 and the water level increased from $1.06 \mathrm{~m}$ at $8: 30$ am to $1.65 \mathrm{~m}$ at 12:30 pm. In addition, drilling activity associated with the natural gas pipeline construction pumped water out of the well during December 10 and 13, 2007. A sharp decrease of water level was caused by water pumping. Only a limited amount of water was pumped out of this well and water supply is scarce at this site. The maximum declining rate is $2.28 \mathrm{~cm} / \mathrm{min}$ and the maximum rate of water level rise is $6.85 \mathrm{~cm} / \mathrm{min}$ during the monitoring period.

Site 3 - Hydrodynamic Changes

Monitoring site 3 is located at a deep well drilled for water supply with a depth of $90 \mathrm{~m}$. Water levels were monitored between February 24 and August 24, 2011 with a measurement interval of 30 minutes and 8784 measurements were collected 
The lowest water level is $8.48 \mathrm{~m}$ below surface during dry season and the highest water level is $1.11 \mathrm{~m}$ below surface during monsoon season in the duration of the monitoring study. The range between the highest water level and lowest water level is $7.37 \mathrm{~m}$. Daily water level change is normally less than $4.57 \mathrm{~m}$. Figure 5 shows water level changes on May 21, 2011. Pumping activity is controlled by the storage of water in the water tower. Water level declines drastically during pumping and recovers relatively fast after pumping has stopped (Figure 5).

The rate of water level change is significantly higher at this site because of a higher pumping rate for water supply. The maximum declining rate is $15.26 \mathrm{~cm} / \mathrm{min}$ and the maximum rate of water level rise is $14.91 \mathrm{~cm} /$ min. Rate changes of at least $10 \mathrm{~cm} / \mathrm{min}$ occurred 128 times during the monitoring period (Figure 6).

\section{Site 4 - Hydrodynamic Changes}

Monitoring site 4 is located at a domestic hand-dug well with a depth of $6.3 \mathrm{~m}$. The distance between site 3 and 4 is $191 \mathrm{~m}$. Water levels were monitored between February 27 and September 2, 2011 with a measurement interval of 30 minutes and 8972 measurements were collected.

The lowest water level is $4.95 \mathrm{~m}$ below surface at dry season and the highest water level is $0.26 \mathrm{~m}$ during monsoon season. The range between the highest water level and lowest water level is less than $4.70 \mathrm{~m}$. Daily water level change is less than $0.19 \mathrm{~m}$. The maximum declining rate is only $0.65 \mathrm{~cm} / \mathrm{min}$ on March 192011 .

\section{Characterization of Sinkhole Hazards Based on Hydrodynamic Conditions}

Sinkhole collapses have occurred in Qingyun village every year in the past decade. No sinkhole cases were reported within $500 \mathrm{~m}$ of site 3 in Jitang village, even though heavy pumping is a common practice due to limited water supplies in shallow karst aquifers. A comparative study of characterization of sinkhole hazard is based on hydrodynamic conditions observed in these two study areas.

Soil cover thickness, hydrodynamic conditions and sinkhole occurrences were listed in Table 1 based on field investigation and monitoring study. Heavy pumping lasted for more than 6 years at site 3. No sinkhole collapses occurred near this site due to sufficient water

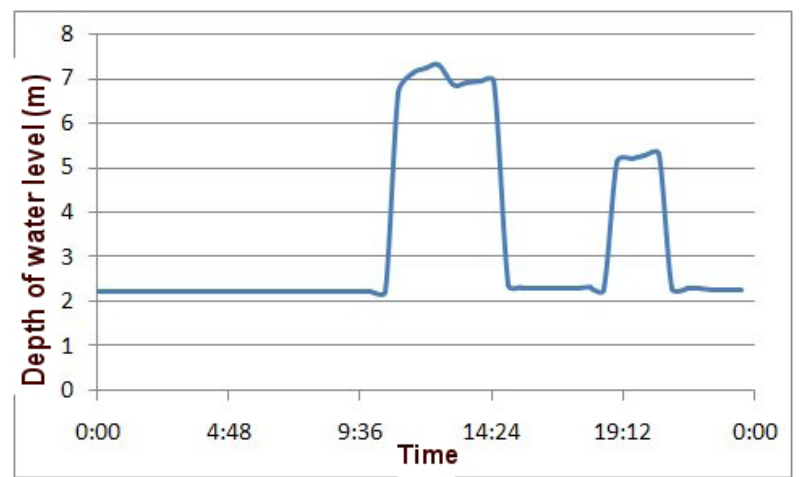

Figure 5. The variation of groundwater level of monitoring site 3 caused by pumping activities on May $21,2011$.

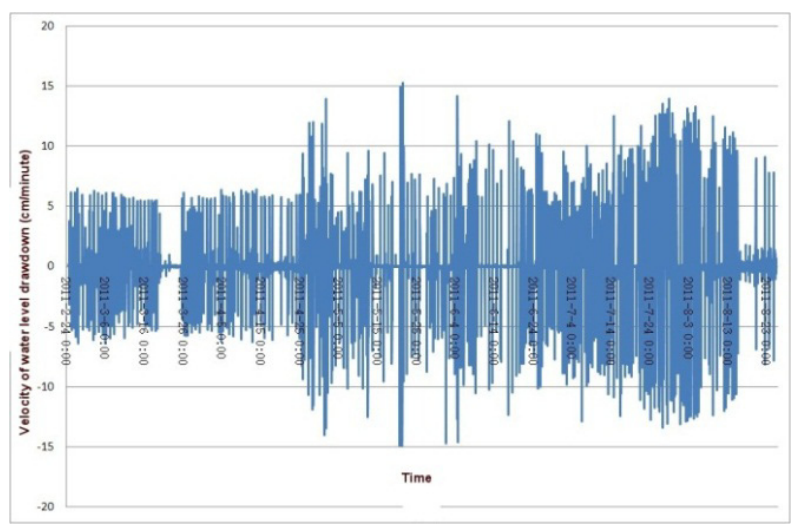

Figure 6. The variation of groundwater level of monitoring site 3.

supply in the deep karst aquifer. Site 1 and 2 are handdug wells to shallow karst water. Pumping activity in this area can cause rapid water level fluctuations and slow recovery due to scarce water supply in shallow karst aquifers, which may cause soil piping and soil void formation and eventually trigger sinkhole collapses.

By comparing hydrodynamic conditions between Qingyun village and Jitang village, characterization criteria of sinkhole hazards are as follows:

(1) Daily water level change and the recovery of water level after pumping:

Daily water level changes reflect the amount of groundwater withdrawn, and the recovery of water level after pumping is related to the amount of water storage and supply in the karst aquifer. The study area is divided into 3 sinkhole hazard areas:

Low risk area: daily water level change is less than $1.0 \mathrm{~m}$ and the recovery of water level is less than 5.0 hours after pumping. 
Table 1. Soil coverage and hydrodynamic conditions in the study area.

\begin{tabular}{|c|c|c|c|c|c|c|c|}
\hline Site & $\begin{array}{c}\text { Thickness of } \\
\text { soil coverage } \\
(\mathrm{m})\end{array}$ & $\begin{array}{c}\text { Rate of } \\
\text { declining } \\
\text { water level } \\
(\mathrm{cm} / \mathrm{min})\end{array}$ & $\begin{array}{c}\text { Time of } \\
\text { water level } \\
\text { recovery } \\
\text { (hour) }\end{array}$ & $\begin{array}{c}\text { Daily water } \\
\text { level change } \\
(\mathrm{m})\end{array}$ & $\begin{array}{c}\text { Maximum } \\
\text { water level } \\
\text { change (m) }\end{array}$ & $\begin{array}{c}\text { \# of sinkholes } \\
\text { within } 500 \mathrm{~m}\end{array}$ & $\begin{array}{c}\text { Connection } \\
\text { between karst } \\
\text { and Quaternary } \\
\text { aquifers (Y/N) }\end{array}$ \\
\hline 1 & 8.0 & 6.58 & 10 & 4.4 & 10.06 & 3 & $\mathrm{Y}$ \\
\hline 2 & 6.0 & 6.85 & 12 & 0.30 & 2.6 & 4 & $\mathrm{Y}$ \\
\hline 3 & 1.5 & 15.26 & 0.5 & 4.57 & 7.37 & 0 & $\mathrm{~N}$ \\
\hline 4 & 1.8 & 0.65 & 5.0 & 0.8 & 4.7 & 0 & $\mathrm{~N}$ \\
\hline
\end{tabular}

Intermediate risk area: daily water level change is $1.0-3.0 \mathrm{~m}$ and recovery of water level is 5.0 -10.0 hours after pumping.

High risk area: daily water level change is greater than $1.0 \mathrm{~m}$ and the recovery of water level is greater than 10.0 hours after pumping.

(2) Maximum declining rate of karst water level: Sudden water and air pressure changes within karst fractures and conduits have been associated with sinkhole collapses in many cases. Model experiment based on geologic settings in several karst areas in Guangxi reveals that severe soil damage would occur when the declining rate of water level is above 180 $\mathrm{cm} / \mathrm{min}$. The rate of water level change in the study area is way below the critical value of 180 $\mathrm{cm} / \mathrm{min}$. Therefore, there is no immediate threat of sinkhole hazard.

More quantitative assessment is needed based on the above criteria. Pumping activities along with ongoing natural gas pipelines may cause significant changes of hydrodynamic conditions in the study area. Real-time monitoring of daily water level changes, water level recovery, and the rate of water level changes will provide guidelines and limit water pumping activities to reduce potential sinkhole collapses.

\section{Conclusions}

A high resolution real-time monitoring system was established to assess sinkhole hazards in this area. Monitoring of water levels of residential and community wells indicate a water shortage in the shallow karst aquifer, which is greatly influenced by precipitation in the study area. By comparing with real-time monitoring of groundwater levels in a referenced area with no sinkhole collapsing event, a characterization process was developed to assess sinkhole hazards in the Qingyun village area. Characterization criteria include daily water level fluctuations of karst aquifer, recovery of water level in karst aquifer, and maximum declining rate of water level in karst aquifer. The characterization process was then applied to the study area to identify and prioritize areas that are most likely to be affected by human activities. The study area is divided into 3 sinkhole hazard areas based on daily water level changes and the recovery of water level after pumping. Realtime monitoring of daily water level changes, water level recovery, and the rate of water level changes will provide guidelines and limit water pumping activities to reduce potential sinkhole collapses due to increased water demand caused by the construction of a natural gas pipeline through Qingyun village.

\section{References}

Gao Y, Alexander EC Jr. 2008. Sinkhole hazard assessment in Minnesota using a decision tree model. Environmental Geology 54(5): 945-956.

Gao Y, Alexander EC Jr. Barnes RJ. 2005. Karst Databa3se Implementation. Analysis of Sinkhole Distribution in Minnesota. Environmental Geology 47(8): 1083-1098.

$\mathrm{Hu}$ C, Chen Z, Chen X. 2003. ANN and GIS Based Regional Prediction of Cover-Collapse Probability: A Case Study in West Part of Guilin City. Earth Science-Journal of China University of Geosciences 28(5): 557-562 (in Chinese).

Lei M, Jiang X. 2000. The risk assessment of karst collapses in urban area-A case study in Liupanshui, Guizhou, China. The Chinese Journal of Geological Hazard and Control 11(4): 23-27 (in Chinese). 
Li G, Li Y, Yang R, Ye J, Zhu C. 2008. Hierarchicfuzzy Prediction and evaluation of karst collapse in Zaozhuang City, Shangdong Province. The Chinese Journal of Geological Hazard and Control 19 (2): 87-90 (in Chinese).

Waltham T, Bell F, Culshaw M. 2005. Sinkholes and Subsidence - Karst and Cavernous Rocks in Engineering and Construction. Chichester (UK): Praxis Publishing.

Zisman ED. 2001. A standard method for sinkhole detection in the Tampa Florida area. Environmental and Engineering Geoscience 7 (1): 31-55. 